\title{
APLIKASI MONITORING KEBERSIHAN SARANA DAN PRASARANA KAMPUS BERBASIS WEB MENGGUNAKAN TEKNIK RESPONSIF PADA ANDROID
}

\author{
Ely Nuryani ${ }^{1}$, Mochamad Yusuf Romdoni ${ }^{2}$ \\ ${ }^{1}$ Prodi Komputerisasi Akuntansi Fakultas Ilmu Komputer Universitas Banten Jaya, \\ ${ }^{2}$ Prodi Manajemen Informatika Fakultas Ilmu Komputer Universitas Banten Jaya \\ Jl. Syeh Nawawi Al Bantani, Curug - Kota Serang - Indonesia \\ 1elynuryani@unbaja.ac.id, \\ 2yusufromdoni@unbaja.ac.id
}

\begin{abstract}
Abstrak - Sarana dan prasarana (sarpras) kampus merupakan aset yang digunakan sebagai penunjang kegiatan belajar mengajar. Sarpras kampus tidak hanya untuk digunakan tetapi perlu dijaga kebersihannya. Namun pada kenyataannya sarpras kampus sering terabaikan dari segi kebersihannya. Terabaikannya kebersihan sarpras tersebut disebabkan oleh beberapa hal seperti kurangnya pengawasan oleh bagian sarpras, sulitnya melakukan pengecekan sarpras dikarenakan jumlahnya yang banyak serta terletak di area yang cukup luas, dan terbatasnya petugas kebersihan. Untuk menangani permasalahan hal tersebut maka dirancang sebuah aplikasi monitoring kebersihan sarana dan prasarana kampus. Pada perancangan aplikasi ini menggunakan metode System Development Life Cycle (SDLC), tahapan-tahapannya adalah perencanaan, analisis, perancangan, implementasi, uji coba, dan penggunaan. Aplikasi yang akan dibangun merupakan aplikasi responsif yang berbasis web dengan platform sistem operasi android. Responsif yang dimaksud adalah salah satu teknik yang digunakan pada pengembangan aplikasi berbasis web agar aplikasi yang dijalankan menyesuaikan pada layar perangkat yang digunakan. Bahasa pemrograman yang digunakan adalah PHP dan MySql dipadukan dengan framework CSS yaitu bootstrap. Aplikasi yang dibangun dilengkapi fasilitas feedback yang dapat digunakan oleh pimpinan berupa komentar dan juga ratting pada setiap laporan kebersihan dari masing-masing unit dan lokasi. Komentar dan rating yang diberikan pimpinan ini dapat memberikan pengaruh secara moral kepada penanggung jawab kebersihan secara langsung. Pada akhirnya perancangan aplikasi ini bermanfaat untuk membantu memudahkan bagian sarana prasarana dan pimpinan dalam memonitoring kebersihan sarana sehingga mampu meningkatkan mutu kebersihan sarana prasarana kampus dan memperlancar proses kegiatan belajar mengajar.
\end{abstract}

Kata kunci : Aplikasi Monitoring, Kebersihan, Responsif.

\section{PENDAhuluan}

Sarana prasarana kampus merupakan modal penting untuk sebuah perguruan tinggi dalam menjalankan fungsi tri dharma terutama dalam hal pendidikan. Sarana prasarana kampus yang memadai diperlukan untuk mendukung dan menunjang kegiatan belajar mengajar. Sarana prasarana kampus sebaiknya bersih dan terawat sehingga meningkatkan kenyamanan para pengguna yaitu dosen dan mahasiswa yang kemudian akan meningkatkan mutu pembelajaran. Kebersihan sarana kampus akan menunjukkan seberapa besar civitas kampus perduli terhadap kebersihan.
Untuk menjaga kebersihan sarpras kampus perlu dilakukan pengawasan secara rutin oleh bagian sarpras dan pimpinan. Namun dengan banyaknya sarpras yang dimiliki dan ditambah luasnya area kampus membuat bagian sarpras dan pimpinan tidak mudah dalam melakukan pengawasan. Bagian sarpras atau pimpinan harus melakukan pengecekan langsung ke setiap sarana atau prasarana untuk memastikan bahwa sarana atau prasarana benar-benar bersih adanya. Hal itu tentu saja membutuhkan waktu dan tenaga yang cukup sehingga seluruh sarpras dapat dimonitor kebersihannya. Tidak hanya itu, petugas kebersihan pun memiliki peran yang sangat penting dalam menjaga kebersihan dan membantu 
pimpinan dalam melakukan monitoring kebersihan sarpras kampus. Petugas kebersihan yang terbatas cukup memadai dalam hal menjaga kebersihan namun tidak mudah dalam melaksanakan pelaporan terkait kebersihan sarpras kampus kepada bagain sarpras atau pimpinan. Pimpinan pun dalam menilai kinerja petugas kebersihan merasa sulit karena tidak adanya media yang dapat digunakan sebagai bahan penilaian pelaporan kebersihan sehingga petugas kebersihan tidak melaksanakan tugasnya secara optimal. Penjelasan tersebut memberikan gambaran bahwa baik petugas kebersihan, bagian sarpras dan pimpinan membutuhkan suatu sarana yang dapat membantu dalam memonitoring kebersihan sarana dan prasarana kampus yang cepat, tepat dan mudah.

Aplikasi monitoring kebersihan sarana dan prasarana kampus dirancang untuk memudahkan petugas kebersihan, bagian sarpras, dan pimpinan dalam memonitoring kebersihan sarpras kampus. Aplikasi yang dibangun merupakan aplikasi yang berbasis web sehingga dapat digunakan oleh user secara realtime. Aplikasi berplatform andoid dan menerapkan teknik responsif sehingga dapat dipakai pada perangkat smartphone atau perangkat lainnya yang compatible. Aplikasi juga mendukung penilaian terhadap laporan petugas kebersihan yaitu dengan tersedianya fasilitas komentar dan rating bagi pimpinan terhadap laporan yang diberikan oleh petugas kebersihan sehingga akan meningkatkan kinerja setiap petugas kebersihan dalam menjalankan tugasnya.

Dari latar belakang yang telah dijelaskan di atas, maka masalah yang akan diselesaikan pada penelitian ini adalah:

1. Bagaimana agar informasi pelaporan hasil monitoring kebersihan sarana dan prasarana dapat diakses dengan mudah dan cepat oleh pimpinan?

2. Bagaimana agar petugas pelaksana kebersihan mudah dalam menyampaikan laporan dokumentasi kebersihan sarana dan prasarana kampus?

3. Bagaimana agar pimpinan mudah dalam memberikan penilaian terhadap hasil laporan kebersihan sarana dan prasarana kampus?

Tujuan penelitian ini secara umum adalah untuk merancang sebuah aplikasi yang dapat digunakan sebagai sarana/alat dalam mendukung bagian sarana prasarana dan pimpinan dalam memonitoring kebersihan sarpras kampus sehingga mampu meningkatkan mutu kebersihan dan memperlancar proses kegiatan belajar mengajar.

\section{Metodologi Penelitian}

Metode pengumpulan data untuk penelitian ini antara lain telah dilakukan beberapa metode yaitu:

1. Riset Kepustakaan

Riset kepustakaan dilakukan dengan mengumpulkan data yang diperoleh dari beberapa buku maupun jurnal sebagai referensi yang sesuai dengan masalah pada penelitian ini.

2. Observasi

Observasi dilakukan secara langsung terhadap sistem berjalan dengan objek penelitian yaitu pada Universitas Banten Jaya.

3. Wawancara

Wawanncara merupakan suatu tindakan pengambilan data dengan cara bertatap muka secara langsung dengan objek penelitian, dengan tujuan untuk mendapatkan informasi secara tepat dan jelas mengenai masalah yang dibahas. Wawancara dilakukan baik dengan petugas kebersihan, kepala bagian sarana dan prasarana, dan pimpinan yang berwenang pada Universitas Banten Jaya.

Metode pengumpulan data yang yang tepat dalam penelitian ini adalah menggunakan metode SDLC (System Development Life Cycle) yang diterapkan dalam suatu basis sistem informasi komputerisasi yang terdiri dari enam fase. Keenam fase dapat dilihat urutan tahap yang berlaku dalam gambar 1 di bawah ini :

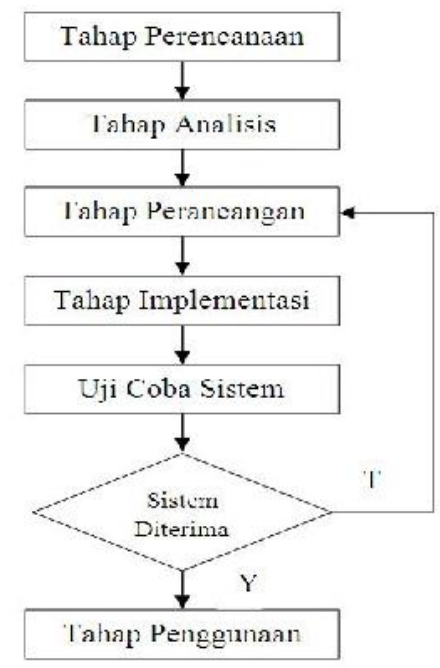

Gambar 1. Bagan Pengembangan System Development Life Cycle (SDLC)

\section{Tahap Perencanaan Sistem}

Dalam tahap perencanaan dilakukan pengumpulan data dan mempelajari landasan-landasan yang akan dibangun. Dalam tahapan ini perencanaan berdasarkan pada Studi Pustaka yang berkaitan dengan aplikasi monitoring kebersihan sarana dan prasarana kampus dengan menggunakan bahasa pemrograman PHP dan MySql dipadukan dengan framework CSS yaitu bootstrap.

Wawancara, melakukan konsultasi maupun tanya jawab secara interaktif kepada pihak Pimpinan Universitas Banten Jaya dan pada bagian sarpras 
selaku bagian yang menangani sarana dan prasarana kampus, serta petugas kebersihan yang bertugas menjaga kebersihan secara langsung. Data-data yang sudah diperoleh kemudian diolah untuk rencana pembuatan aplikasi.

\section{Tahap Analisis Sistem}

Pada tahap analisis dilakukan pengidentifikasian terhadap tujuan dan kebutuhan sistem yang akan dibangun. Hal ini diperlukan untuk acuan dalam penyusunan aplikasi monitoring kebersihan sarana dan prasarana kampus. Domain Understanding merupakan kegiatan yang dilakukan dalam menganalisis yaitu dengan memahami alur penyampaian informasi yang sedang berjalan, mengidentifikasi permasalahan pada sistem yang berjalan dan mencari kesimpulan dari proses analisis yang telah dilakukan.

Hasil identifikasi terhadap tujuan dan kebutuhan sistem serta permasalahan pada sistem disajikan menggunakan diagram tulang ikan sebagai berikut:

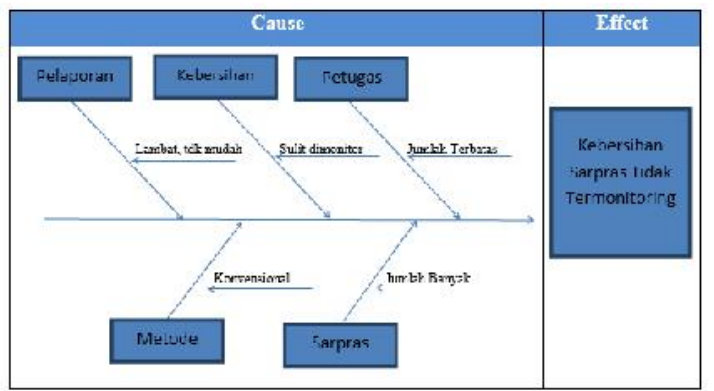

Gambar 2. Digram Tulang Ikan

\section{Tahap Perancangan Sistem}

Tahap perancangan aplikasi monitoring kebersihan sarana dan prasarana kampus dilakukan sesuai dengan apa yang telah direncanakan. Spesifikasi yang dibuat cukup rinci sehingga pada tahap implementasi tidak diperlukan keputusan baru dan menggunakan apa yang sudah ditentukan pada tahap perancangan. Perancangan terbagi menjadi tiga, yaitu:

1. Rancangan Database, pada aplikasi yang akan dibangun belum tersedia database maka database akan dirancang sesuai dengan kebutuhan. Kegitankegiatan yang berkaitan dengan perancangan database pada penelitian ini antara lain adalah:

- Selection yaitu memilih dan menentukan atribut data yang diperlukan.

- Addition yaitu ada kalanya perlu ditambahkan sebuah atribut baru untuk mencapai tujuan pembangunan sistem.

- Data cleansing yaitu kegiatan mendeteksi dan mengoreksi data dalam basis data yang tidak benar, tidak lengkap, formatnya tidak tepat, atau berlebihan.
- Transformation yaitu transformasi atau pengubahan bentuk dilakukan untuk mendapatkan data yang konsisten.

- Data mining, yaitu menentukan tipe dan algoritma yang akan dipakai.

2. Rancangan Sistem Secara Umum, Rancangan sistem secara umum adalah mendeskripsikan sistem yang sedang dibangun secara umum. Untuk mendeskripsikan sistem yang dibangun dalam penelitian ini menggunakan media pemodelan UML (unified modelling language).

3. Rancangan Sistem Secara Detail, Perancangan sistem secara detail merupakan perancangan formform yang digunakan sebagai media komunikasi dengan penggunaan sistem yang ada.

\section{Tahap Implementasi Sistem}

Tahap ini merupakan tahap meletakan sistem supaya siap untuk dioperasikan. Aktivitas pada tahap penerapan terdiri dari pemrograman sistem yang diimplementasikan kedalam bahasa pemrograman PHP dan MySql sebagai pengolahan database dipadukan dengan framework CSS yaitu bootstrap agar aplikasi bersifat responsif.

Tindak lanjut dari implementasi sistem ialah dengan melakukan pengetesan menggunakan data yang sesungguhnya dalam jangka waktu tertentu yang dilakukan bersama-sama dengan pemakai.

\section{Tahap Uji Coba Sistem}

Pengujian sistem dilakukan setelah pembuatan modul sistem selesai dibuat dengan percobaan pada komputer user interface. Dengan melakukan uji coba ini dapat diketahui kekurangan sistem yang telah dibuat, diantaranya: apakah sistem yang dibuat berjalan dengan baik, apakah sistem yang dibuat sesuai dengan perancangan pada sistem yang dirancang, dan apakah penanganan kesalahan berfungsi dengan baik. Pengujian sistem sangat penting dilakukan secara keseluruhan. Testing testing harus dilakukan secara sistematis dan hasilnya didokumentasikan dengan cermat.

\section{Tahap Penggunaan}

Setelah sistem melalui tahap uji coba maka sistem dapat sepenuhnya menggantikan sistem lama. Selain sistem dapat digunakan, sistem harus dipelihara antara lain agar masalah-masalah yang tidak terdeteksi selama masa uji coba dapat diatasi; disesuaikan dengan perubahan bisnis dan lingkungan; serta memelihara kinerja sistem tetap stabil. 


\section{HASIL DAN PEMBAHASAN}

Pada tahapan ini dilakukan analisis terhadap sistem yang terdiri dari beberapa proses yang dibutuhkan di dalam mengatasi permasalahan yang terjadi pada monitoring kebersihan Sarana dan Prasarana di lingkungan Universitas Banten Jaya. Adapun kebutuhan dari beberapa proses tersebut harus di integrasikan langsung terhadap software yang dibangun sebagai berikut:

\section{A. TAHAP ANALISA}

1) Halaman Depan

a. Sistem mempunyai halaman publikasi posting kebersihan dari Unit Kerja, Lokasi dan User. Publikasi ini disertai judul, keterangan, tanggal dan gambar hasil photo secara langsung terhadap objek kebersihan.

b. Terdapat halaman autentifikasi login sebagai pintu keamanan terhadap pengguna yang tidak memiliki hak akses terhadap aplikasi.

2) Halaman User Admin

a) User Admin dapat melihat halaman utama (Dashboard) serta mengolahnya.

b) User Admin dapat menambah data User serta mengolahnya.

c) User Admin dapat menambah data lokasi serta mengolahnya.

d) User Pegawai dapat menambah posting kebersihan serta mengolahnya.

e) User Pegawai dapat merubah data user dirinya.

f) User Pegawai tidak dapat merubah data postingan user lain.

g) User Pimpinan dapat memberikan rating serta komentar terhaadap seluruh posting kebersihan suatu objek dari setiap pegawai.

\section{B. DESAIN}

\section{a) Desain System}

Use Case Diagram

Use Case Diagram merupakan gambaran fungsionalitas dari suatu sistem dengan menggambarkan sejumlah exsternal actors dan hubungannya ke Use Case yang diberikan oleh sistem dalam bentuk simbol dan teks sebagai dokumentasi, sehingga mudah dipahami mengenai kegunaan sistem.

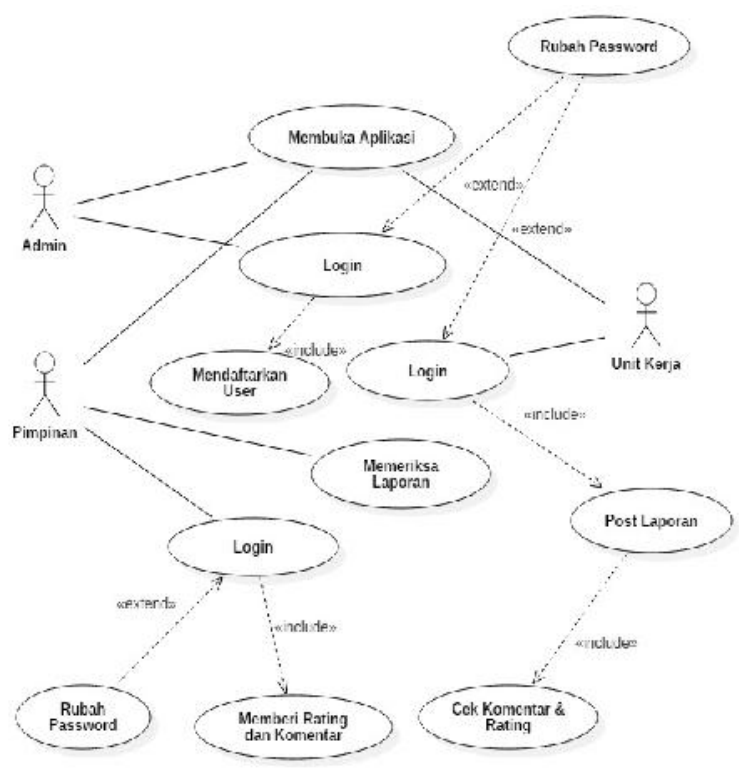

Gambar 3. Use Case Diagram

Activity Diagram

Activity Diagram Menggambarkan rangkaian aliran kerja dari aktivitas yang digunakan untuk mendeskripsikan aktivitas yang dibentuk dalam suatu operasi pada suatu sistem yang akan dijalankan.

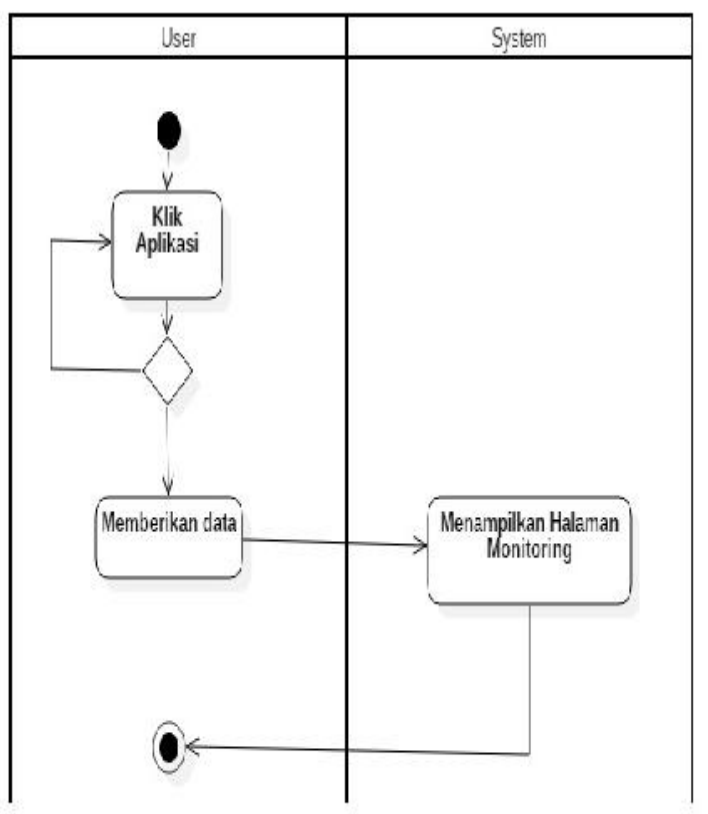

Gambar 4. Diagram Activity Menampilkan Halaman Monitoring 
Gambar 6. Diagram Activity Daftar User

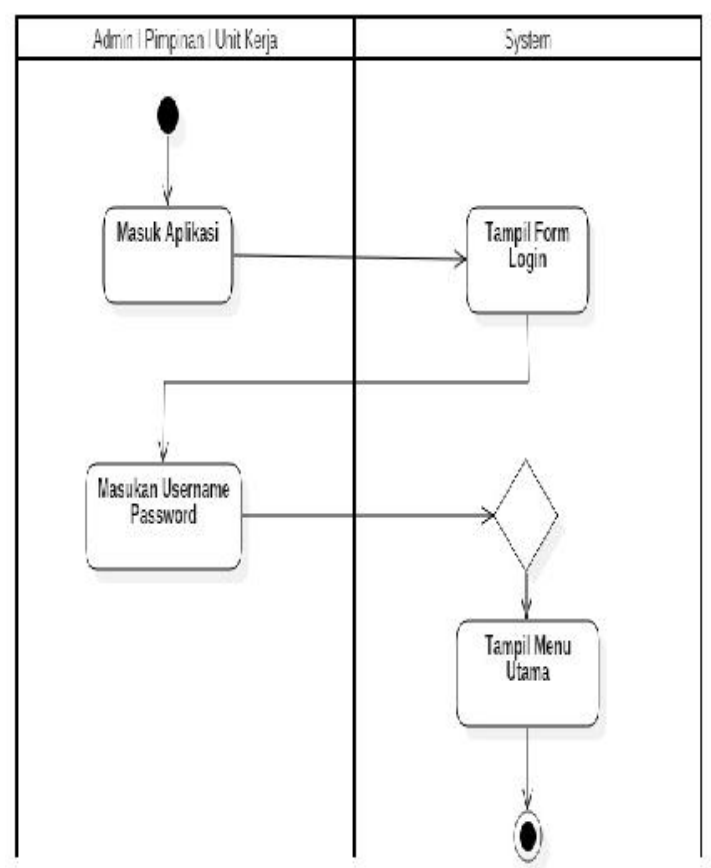

Gambar 5. Diagram Activity Login

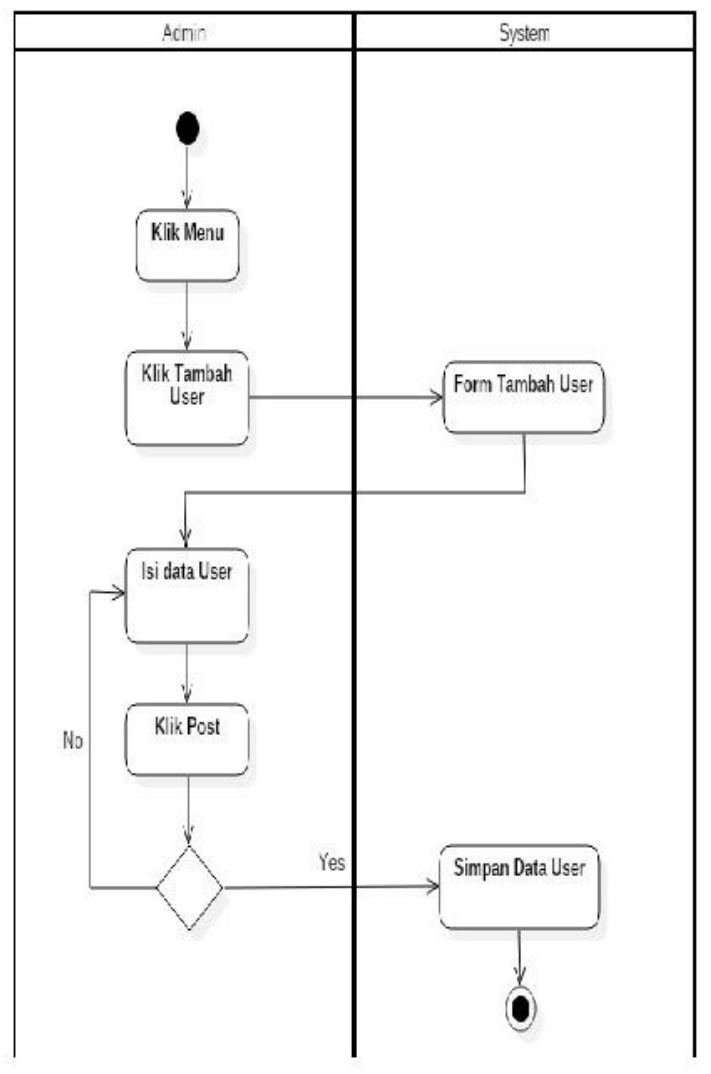

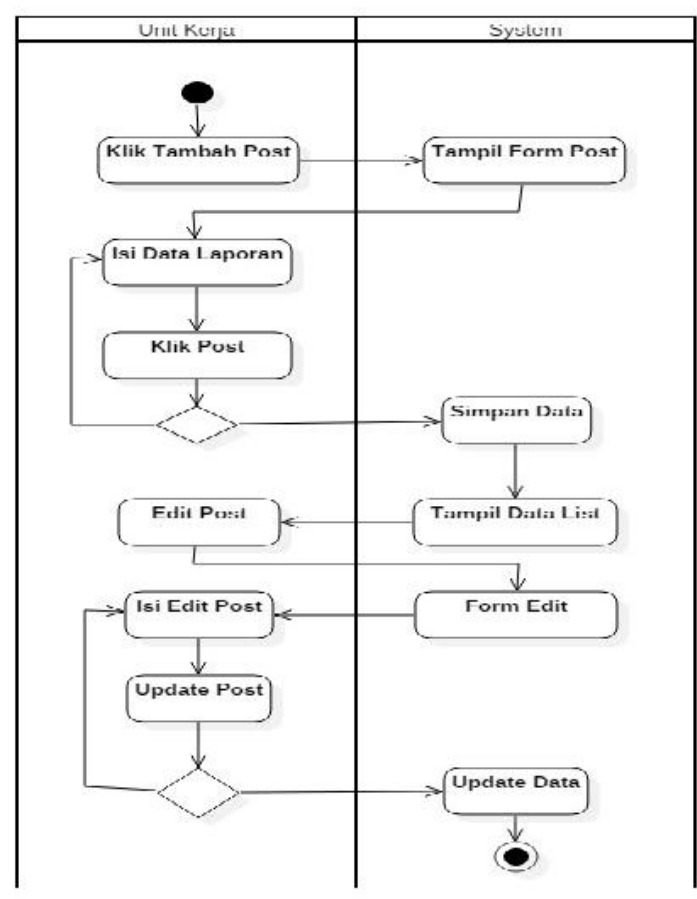

Gambar 7. Diagram Activity Posting Kebersihan

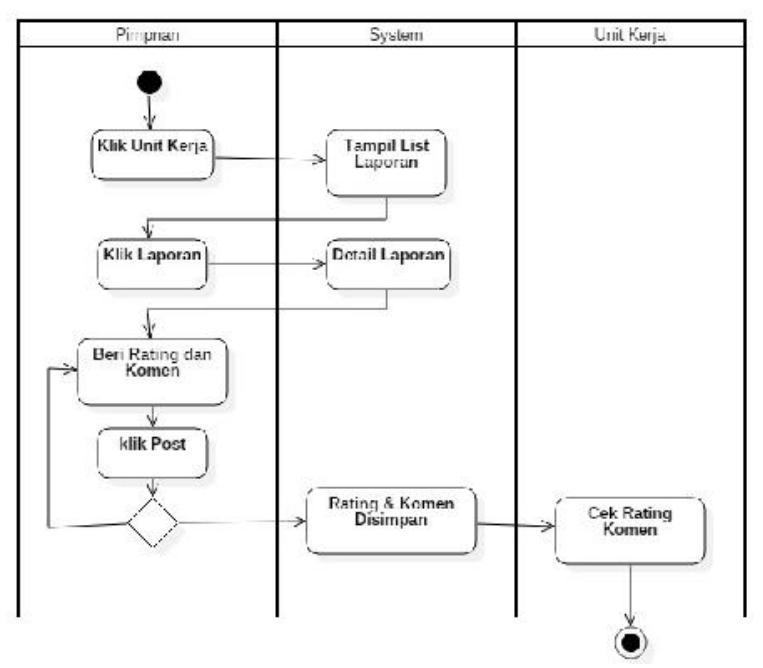

Gambar 8. Diagram Activity Pemberian Rating \& Komentar

Sequeence Diagram

Suatu diagram yang menjelaskan interaksi dan komunikasi diantara objek-objek, yang terdapat pada sistem monitoring kebersihan diagram ini juga menunjukkan serangkaian pesan yang dipertukarkan 
oleh objek - objek yang melakukan suatu tugas atau aksi tertentu.

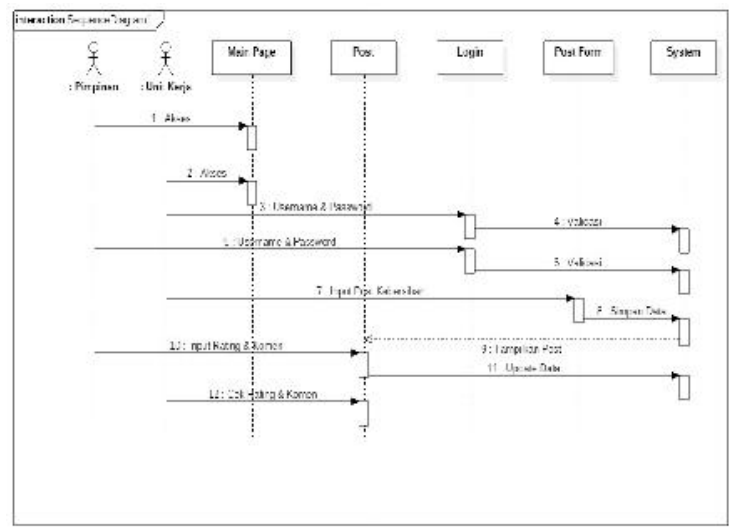

Gambar 9. Sequeence Diagram Monitoring Kebersihan

\section{b) Logical Record Structure}

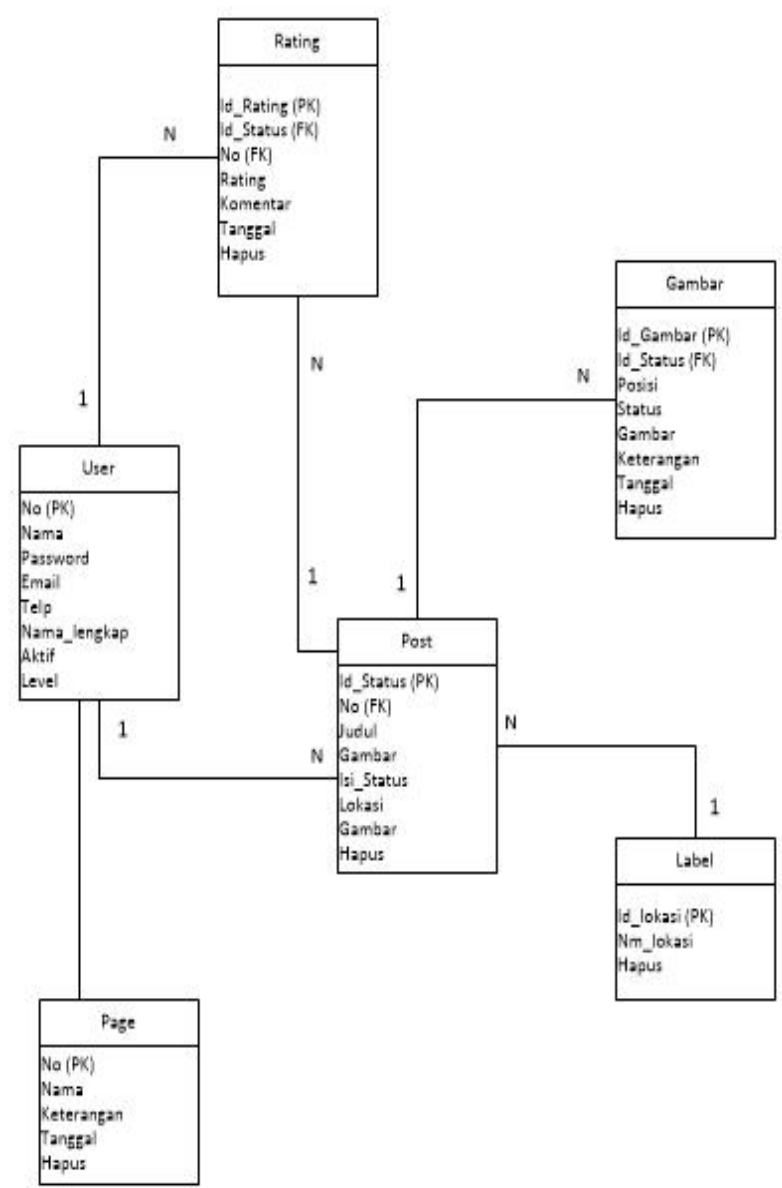

c) IMPLEMENTASI

$11.44 \%$ 目 0 $4 G \Delta 4 G^{40}$

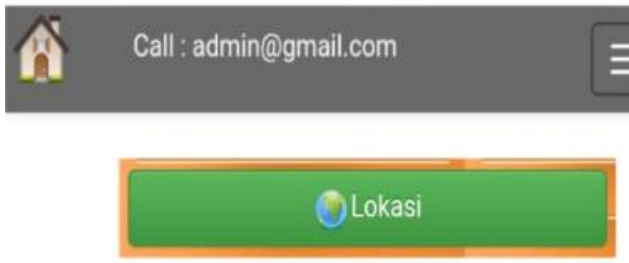

Lantai 1 Gedung A (1)

Lantai 2 Gedung A (1)

Rektorat (1)

Yayasan (1)

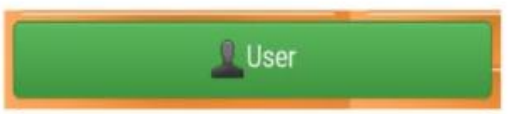

Ely Nuryani (3)

Yusuf Romdoni (1)

\section{Ruang Rapat Yayasan}

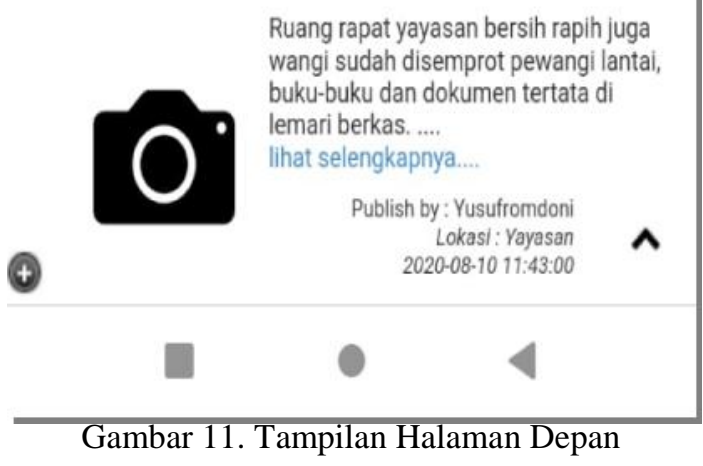

Gambar 10. Logical Record Structure 
$11.44 \stackrel{0}{0} 0$.

$4 G \Delta 4 G^{40}$

๑ (i) iet1.yusufromdoni.com 2 :

Silahkan Masukkan Username dan

Password Anda

Username

Yusufromdoni

Password

Silahkan Register untuk bergabung

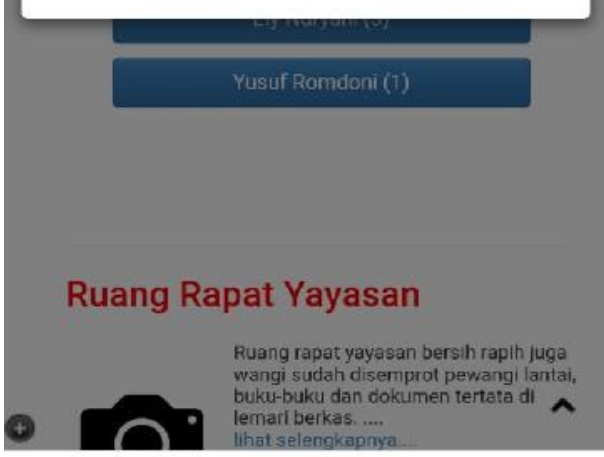

C

Gambar 12.

Tampilan Halaman Login

$$
77.43 \text { ㄴ..ㅂ. } 4 G 44 G=4
$$

D. (1) iet7 yusuframdanicam (2) इ

\section{쇼}

Silahkan Mesukkan Judul

Lantai 1 Gedung A

File - Edit - insert - View - Format -

Table - Tools -

$4 \rightarrow$ Farmats- B $T$

豆 $\overline{\underline{\underline{2}}}$

i

Post

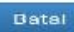

क

Gambar 13.

Tampilan Input Posting Kebersihan

\section{h}

Ruang Rapat Yayasan

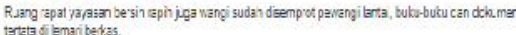

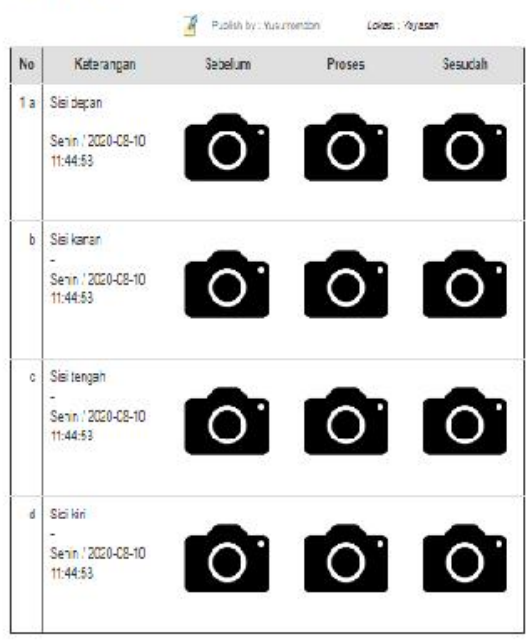

Gambar 14.

Tampilan Halaman Update Photo

12.00 回要目。

$4 G \triangle 4 G^{40} \triangle$

\section{Ruang Rapat Yayasan}

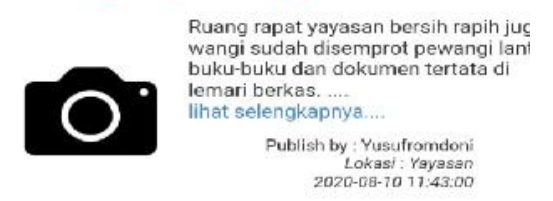

Ruang Rektorat Kampus 1

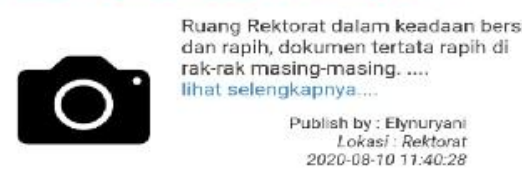

\section{Ruang A21 Gedung A}

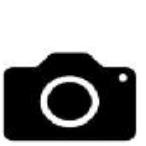

Lantai dalam keadaan bersih, bangk ard bersih

lihat selengkapnya..

Publish by : Elynuryan
Lokasi: Lantai 2 Gedung 2020-08-10 11:39:20

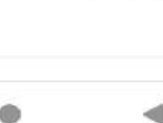

Gambar. 15

Tampilan Halaman Posting Kebersihan 


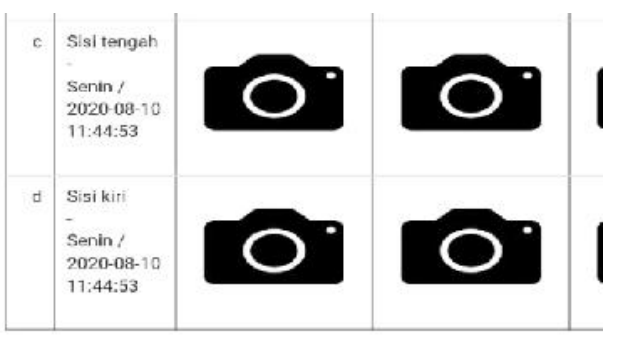

Beri Rating Laporan

Silahkan login sebagai admin untuk review laporan

Total Rating 4 / 5

oleh: Pimpinan

10 Augus! 2020

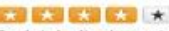

Sudah baik, tinggai dicek area kolong rak

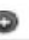

Gambar 16. Tampilan Rating \& Komentar

\section{KESIMPULAN}

Berdasarkan penelitian yang telah dilakukan, maka dapat disimpulkan sebagai berikut:

1. Aplikasi monitoring yang telah dibangun berbasis android dapat diakses dengan mudah oleh pimpinan sehingga mempermudah pelaksanaan monitoring kebersihan sarana dan prasarana.

2. Aplikasi monitoring yang dibangun dioperasikan dengan smartphone sehingga petugas pelaksana kebersihan mudah dalam menyampaikan laporan dokumentasi kebersihan sarana dan prasarana kampus.

3. Aplikasi monitoring dilengkapi dengan fasilitas pemberian rating dan komentar sehingga pimpinan mudah dalam memberikan penilaian terhadap hasil laporan kebersihan sarana dan prasarana kampus

\section{REFERENSI}

[1] Dinata, I., \& Sunanda, W., (2015). Perancangan Sistem Monitoring Konsultasi Bimbingan Akademik Mahasiswa dengan Notifikasi Realtime Berbasis SMS Gateway. Jurnal Nasinal Teknik elektro, 4 (1). Darihttp://jnte.ft.unand.ac.id/index.php/jnte/article/v iew/120

[2] Junaidi, J., Anugrah, L., \& Pancasakti, A. D., (2015). Model Aplikasi Monitoring Sistem Absensi Sidik
Jari Sebagai Pendukung Keputusan Untuk Penilaian Kinerja Pegawai. Proceedings Konferensi Nasional Sistem dan Informatika. Dari http://www.ejournal.stikombali.ac.id/index.php/knsi/article/view/509

[3] Mercy Corps, (2007). Monitoringand Evaluation (DM\&E) Guidebook. Mercy Corps.

[4] Mulyadi, (2007). Sistem Perencanaan dan Pengendalian Manajemen. Jakarta: salemba Empat.

[5] Nasrudin Safaat. 2012. Sistem Informasi Berbasis Android, Yogyakarta : Andi Offset.

[6] Pradika, R., Affandi, A., \& Setijadi, e., (2013). Rancang Bangun Aplikasi Monitoring Jaringan dengan Menggunakan Simple Network Management Protocol. Jurnal Teknik ITS, 2 (1). Dari http://www.ejurnal.its.ac.id/index.php/teknik/article/ view $/ 2265$

[7] Putra, A. S., Sukri, H., \& Zuhri, K., (2018). Sistem Monitoring Realtime Jaringan Irigasi Desa (JIDES) Dengan Konsep Jaringan Sensor Nirkabel. Indonesian Journal of Electronics and Instrumentation Systems, $8 \quad$ (2). Dari https://journal.ugm.ac.id/ijeis/article/view/39783

[8] Sari, M. W., \& Wardani, S., (2016). Rancang Bangun Aplikasi Monitoring Detak Jantung Melalui Finger Test Berbasis Arduino. Jurnal Eksplorasi Karya Sistem Informasi dan Sains, 9 (2). Dari https://labti.ukdw.ac.id/ojs/index.php/eksis/article/vi ew/502/232

[9] Wrihatnolo, R. R., \& Dwijowijoto, R. N., (2008). Manajemen Privatisasi BUMN. Jakarta: Elex Media Computindo. 